\title{
The Intensification Of Learning Uzbek Language Using Moodle Technology
}

\author{
Dilnoza Yuldasheva, \\ $(\mathrm{PhD})$ Associate Professor, Researcher at «Silk Road» International University of Tourism. Samarkand, Uzbekistan \\ dilnoza.yuldasheva@univ-silkroad.uz \\ orcid.org/0000-0002-3898-2113
}

\begin{abstract}
The theme of the article is «The intensification of teaching Uzbek language using Moodle technology». Be that as it may, indeed these days the impact of computerization influences by implication points and substance of tall instruction committed to Uzbek language. Educator of unused era ought to be able to select and utilize computer innovations which suit substance and purposes of instructing and which is able to offer assistance understudies to succeed in agreeable way taking into thought their identities. So, investigation of inquire about considers appears us, that in show disdain toward of significant progression in realization of diverse computer advances, their potential is utilized inadequately since of need of data around mixed media fabric, calculation of its planning and methodological suggestions how to utilize it. Subsequently, inadequately availability of strategy in educating Uzbek with the assistance of computer advances is the most reason of choice this issue for our inquire about. It comprises in look and realization of diverse sorts of computer advances which is able be able to make strides level of students' information on Uzbek. Moodle framework have started to play a progressively critical part within the educating of Uzbek language. Its utilize in this setting is bolstered by a developing body of inquire about that highlights the significance of the transaction of meaning and computer-based interaction within the prepare of educating language. Some methodologists point out the significance of computer innovation amid the method of cognition. It permits understudies to secure language in significant settings for particular purposes. The purpose of this work is hypothetical and viable examination of major strategies of utilizing computer innovations and recommendation Moodle framework within the prepare of instructing Uzbek.
\end{abstract}

Keywords and phrases:

information society, technological revolution, multifunctional, demands, control, rating, correction

Article Received: 18 October 2020, Revised: 3 November 2020, Accepted: 24 December 2020

The beginning of the third millennium is characterized as a transition to the «information society», having the new structure, in which the decisive role is played by industries related to the receipt, distribution and processing of information $[1 ; 51]$. This transition is connected with the new «technological revolution», which is characterized by generalized computerization and informatization of society.

For the dynamic development of information society, the development of human resources is necessary that can meet the requirements of the information age through education and lifelong learning to meet the growing demand for professionals in the field of information technology $[2 ; 86]$. That's why it's necessary to pay greater attention to basic education, acquired in secondary institutions. We cannot deny that information changes, which we face nowadays, are global. Moreover, it's obvious that there is a necessity of reconsideration of approaches to education as a whole system.

Modern development of pedagogics, its freedom from stereotypes and innovative orientation require creative integration of up-todate methods. Informatization of system of education is a process which provides this field with theory and practice of usage of new Moodle technology. The matter is that it is oriented on realization of psychological and pedagogical goals of teaching. The use of this technology in the educational process not only improves the performance level of digestibility of material by 
students, but also develops their knowledge of the potential of emerging information technologies.

Analysis of material which is discussed on international scientific conferences shows us that the purpose of education isn't just knowledge and skills, but also definite qualities of personality. Post-industrial society is interested in ability to take decisions, adapt to varying conditions of life, act on one's own etc.

However, according to the opinion of E.S. Polat, who is the author of researches on teaching foreign languages, including the method of projects, «solution of these tasks was rather difficult because of absence of real conditions for carrying out, in consideration of traditional approach to education which focuses on classlessons system» $[1 ; 13]$. She supposes that the main task of higher education does not consist in the content of education, but in usage of new technologies of teaching.

Let us take the concept of «projecting» (latin «projectus» - thrown ahead). Speaking about it, we should pay heed to the fact, that this isn't a new word in pedagogical theory. This definition appeared at the end of 70-s in the context of new program which was offered by Royal college of Art in the Great Britain.

Rely on notions of projecting and technologies of teaching, Polat considers methodology of projects as a complex of reconnaissance, problem, creative methods which develop imagination and at the same time they form personality of pupils $[1 ; 67]$.

Nowadays we have a computer era here. And the function of Moodle projects is carried out by many programs and one of them is Microsoft Power Point. This innovation devise includes the best experience of the past and something completely new and effective of our present. Beyond any doubt, the approach of unused innovations in learning prepare is continuously energizing. They include modern measurements to the lesson and start understudies to higher level of inspiration and accomplishment.

One of the most effective areas of usage of Moodle technology is the lessons of Uzbek language. Saying it, we cannot keep from mentioning that citizens of Uzbekistan should know 3 languages. This is dictated by the necessity and it was repeatedly told by the President of the Republic Shavkat Mirziyoev. The trends of globalization, global integration in various fields of economic, technical, cultural, social and personal life make great high demands of the practice of Uzbek language [4; 47].

Because of changes in the content of education, the priority role in teaching and educational process belongs to information and communication technologies. Usage of them gives us tremendous opportunities of Moodle system as a tool for teaching. Moodle framework has numerous focal points over conventional strategies of educating. It permits you to prepare distinctive sorts of exercises online, and blend them in different combinations. They offer assistance to get it the marvel of language, frame the linguistic capacity to make communicative circumstances, to computerize discourse, and as well, they give the opportunity of driving of agent framework, the realization of person approach and the heightened of independent work of students [5; 54].

Moodle framework has started to play an progressively vital part within the instructing of Uzbek language. Its utilize in this setting is supported by a developing body of investigate that highlights the significance of the arrangement of meaning and computer-based interaction within the handle of instructing language. Larger part of methodologists point out the significance of computer innovation amid the method of cognition. It permits students to obtain dialect in important settings for particular purposes.

There are 2 fields of application of Moodle during the process of teaching: Moodle support of traditional education and education which is realized with the help of a computer.

Moodle system can be used by a teacher for solving some didactic tasks which he can face during the lesson:
a) Presentation of information in different forms; 
b) Formation of common and special knowledge and skills on the subject;

c) Control, rating and correction of results of teaching;

d) Organization of individual teaching and group teaching;

e) Running of the process of teaching.

Moodle system can be used during all stages of teaching: explanation of new material, its revision and control.

Computerization of the process of teaching influences greatly on all components of modern educational system and surely, on the subject «Uzbek language» too: its aims, tasks, content, methods, technology.

Teaching Uzbek language with the help of Moodle system differs and has its own advantages:

- Students are interested in the process of teaching and in result, it leads to high motivation of learning;

- Students eagerly «communicate» with computers and it increases not only computer but also linguistic culture;

- Individualization of teaching;

- Moodle system does not show negative emotions if a student repeats his mistakes;

- Objectivity of marks.

It means that, when we use Moodle system during the lesson of Uzbek, a teacher is not only carrier and owner of information. It's much more important to show his creative approach to interpretation of Moodle program. This technology allows combine successfully different forms of organization of educational process. It promotes better interaction among students and also the role of a teacher takes another position. Instead of supervisor he becomes an equal partner and adviser who is always ready to help in the mastering Uzbek language.

The main task of students is not just getting new knowledge but formation of skills which will allow to work with information. We should not forget that traditional method of teaching is good because of communicative aspect which is realized more effectively. That is why it is necessary to combine computer technologies with traditional teaching.

Moodle system is regarded as a tool to improve motivation, builds strong language skills and improve the knowledge of Uzbek language. Moodle system stirs up all three channels of perception: auditory, visual and kinesthetic that allows to increase the volume and durability of learning new material, it greatly improves the status of students in the teaching process, increases the cognitive activity of them and supports the interest to the subject $[6 ; 25]$.

Multimedia training programs for Uzbek language use different techniques to conduct familiarization, training and supervision of knowledge and skills of students. Usage of multimedia programs does not exclude the traditional teaching methods, it's combined harmoniously with them at every stage of education [5; 47].

Usage of Moodle system allows a teacher not only to improve the effectiveness of learning, but also encourage students to learn Uzbek in the future. These lessons include interactive multimedia content, which allows a teacher to involve students in the learning process promoting interest to the studied subject, and better assimilation of the material.

Moodle system allows to conduct classes at a qualitatively new level. Visual richness of the educational material makes it vivid, and convincing. Computer presentations allow students to focus attention on important points of information and create a visual effect in the form of illustrations, charts, diagrams, graphic compositions [6; 213].

For creating of lessons, teacher needs to know at least basic knowledge of software applications. According to the fact that lessons with multimedia applications are not so developed in ready materials, a teacher should create missing elements $[3 ; 18]$. The computer in this case will perform the following functions:

1. Moodle system as a simulator in the process of formation of skills. In order to reach this aim the following programs are used: 
- The Microsoft Word - for exercises of spelling of the studied words, building of sentences, the transformation of the sentences and execution of exercises.

- The Microsoft Power Point - using means of this program you can create good exercises for the introduction of new vocabulary and grammar. For example: presentation (lexicon and / or grammar) + a series of exercises (with the control right - wrong) + sound + control test or exercise.

- The Microsoft Excel - with the help of this program you can also create similar exercises with an assessment of the testing, the number of errors made, the return to the incorrect executed sentences.

- The Windows Movie Maker - a program for creating / editing videos. It's included in the software of Microsoft Windows, beginning with Windows ME. With the help of this program, it's possible to make slide-shows, edit video, overlay soundtrack, add titles and subtitles etc.

2. Moodle system - as a visual aid for the teaching and learning:

- The Microsoft Power Point - the most convenient and simple program for people who do not know programming. With the help of this program you can produce materials of countryspecific features, introduce new vocabulary, grammar rules etc.

- The Microsoft Excel - used to show charts, graphs, summary tables.

3. Moodle system - as a source of educational information:

- Program Microsoft Word - is used for presentation of the texts in Uzbek, information for discussion and debate.

- The Microsoft Excel - for the various charts, graphs, for the analysis and conclusions.

- The Microsoft Power Point - is used to demonstrate new material. Effecting on all types of memory (auditory, visual and kinesthetic), such presentation of information is very effective. It can breathe new life into plans of old lessons and improve students' motivation because in contrast to simple text they may be added with pictures, animations, sounds etc. The secret of this program consist in fact that it's based on rather effective and interesting classical method - method of projects.

Thanks to high level of interactivity, Moodle system creates unique informative environment, which can be used for solution of didactic tasks during the process of teaching Uzbek (for example: cognitive, informational, cultural). This is one of the most important advantage of computer technologies. They enclose electronic informative environment, allowing to work with Moodle system as with universal device for information processing.

Since of its oddity Moodle framework changes fair standard errand into an experience, spurring learners to memorize a dialect since the instructor who employments that «genius tool» in his lesson can utilize diverse and indeed more energizing modes than the course book to show modern materials with content, sound video and hypertext offices advertising high-quality intelligently criticism on vocabulary, linguistic use, language answers, culture issues, etc., at whatever point the student feels he needs it.

In conclusion, the reality that the securing prepare is related to the exertion to communicate or translate implications and cannot thrive in exercises which concentrate on shapes has driven a few commentators on computer-assisted learning to state Moodle framework ought to be utilized for formal linguistic use penetrating which favor learning, in this way discharging the instructor to run such forms of movement which is able upgrade securing. This combination of instructor and computer sounds sensible. Instructors are great at passing on and translating implications. Computers are great at forms which require understanding redundancy and consideration to detail. Thus, we cannot keep from underlining that cooperation of teachers and Moodle system is quite effective during the process of teaching Uzbek.

\section{Bibliography:}

[1] Полат Е.С. Новые педагогические и информационные технологии в системе образования, 2000 с. 67 
[2] Новые педагогические и информационные технологии в системе образования: Учеб. пособие для студентов пед. вузов и системы повышен. квалифицир. пед. кадров / Е.С. Полат, М.Ю. Бухаркина, М.В. Моисеева, А.Е. Петров. - М.: Академия, 2019. - с. 13, 67

[3] Pope C., \& Golub J. (2019). Preparing tomorrow's language arts teachers today: Principles and practices for infusing technology. Contemporary Issues in Technology and Teacher Education. citejournal.org/vol1/iss1/currentissues/artic le1.htm

[4] A.Hojiyev. Hozirgi o'zbek adabiy tili. I. Toshkent, 1980.

[5] http://www.mediainfo.com/emedia/

[6] http://cnn.com/worid

[7] http://www.abcnews.go.com/index.html 